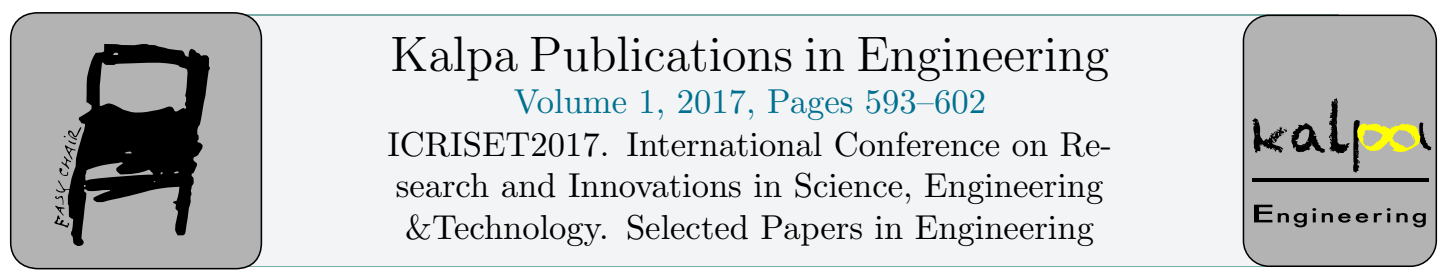

\title{
Comparative Analysis of Series \& Parallel Passive Filter Using PSCAD Simulation
}

\author{
Ronak R. Jayswal, Swapnil S. Marathe, Manank A. Shastri and Kiran V. Panchal \\ Student, Electrical Engineering Department \\ Sardar Vallabhbhai Patel Institute of Technology, Vasad, Gujarat, India
}

\begin{abstract}
Harmonic filters will become an inevitable equipment in power system in not too distant future, given the alarming power quality degradation due to the current harmonics and voltage harmonics; keeping this as a datum scenario, rise of filters will be followed in coming years. In this paper, essential data demonstrating the swelling use of power electronic components into various fields, viz. industrial and power sector side are initially discussed. Several studies have been illustrated for the mitigation of industrial bound harmonics (produced due to non-linear loads) with key focus inclining towards passive filters. Passive shunt and passive series topologies have been analyzed. According to the results derived from the analysis and the detailed comparison of the topologies discussed, final verdict has been provided based on various economic oriented parameters such as cost effectiveness, size, power consumed, initial spikes, THD and more are covered in the final section of the paper.
\end{abstract}

Keywords-Total Harmonic Distortion (THD), passive harmonic filter, passives shunt filter, passive series filter, non linear load, harmonics.

\section{Introduction}

Given the fact that the application of power electronic devices in industries and commercial areas (aerospace, residential, industrial, commercial, telecommunication, transportation, utility system, electric drives) is increasing day by day, and in the rush for compact manufacturing devices, the need of such devices has witnessed a sharp increase. Also, the lighting loads, which includes choke coil, Switching Mode Power Supply (SMPS), arc furnace, computers, controllers, Uninterrupted Power Supply (UPS), battery chargers, drives, etc form a major part of non-linear loads. Non-linear loads are those loads whose impedance changes as the voltage changes. So, these loads would not draw sinusoidal current even if the applied voltage is sinusoidal. Hence such loads would create distortion in current and voltage waveforms, harmonics and thereby degrading the overall power quality of the ystem. Hence the alleviation of harmonics is must and once such method is filter (active, passive) [5]. 
Passive filters contain combination of resistor, inductor and capacitor, either in series, parallel or hybrid. Working of passive filters depends mainly on two mechanism - low impedance or high impedance path and resonance. [3] The ultimate goal is to bring down and maintain the THD as per IEEE 519 (2014). The advantages of shifting to passive harmonic filters rather than the active filters is its cheapness, robustness, and simplicity in manufacturing. However, there are some disadvantages such as non -autonomous and non-suitability for universal input range. Also, use of bulky and heavy magnetic materials is to be done; one passive filter deals with a particular order of harmonic that is to be removed. Hence, as the requirement to eradicate more number of odd harmonics arises, more number of passive filters are to be assigned to deal with them. Thus, flexibility in its operation is not achieved. Various topologies and their analysis are described herewith as follows.

\section{Basic Passive Filter Topologies}

The main topologies for passive harmonic filters which are discussed and analyzed here are: passive shunt filter and passive series filter [1][2]. The working of these filters depend upon the RLC or LC tuning for a particular frequency, measured in Hertz $(\mathrm{Hz})$, called resonance. The series resonance happens when the capacitive reactance and inductive reactance are of same magnitude, but because of the fact that they are opposite in phase, they will cancel each other's effect and the cumulative reactance effect on the total impedance will be neutralized. Parallel resonance is said to have occurred when reactive (or wattless) component of line current becomes zero. The frequency at which reactive part of the impedance becomes zero is called resonant frequency, such as $250 \mathrm{~Hz}$ for $5^{\text {th }}$ order harmonic, and $350 \mathrm{~Hz}$ for $7^{\text {th }}$ order harmonic.

\subsection{Passive Series Filter}

The passive series filter incorporates the application of parallel resonance mechanism [8]. The RLC combination, acting as a series resonance for the passive harmonic filter is connected in series with the input power supply and the load (Variable Frequency Drive cascaded induction motor).

Series filter acts as a rejecter circuit, hence it will not allow the current waveforms of tuned frequency. That is, if the filter is designed to mitigate $5^{\text {th }}$ and $7^{\text {th }}$ order harmonic, the filter will block all the corresponding order current waveforms trying to go further it, because of the high impedance offered by the filter.

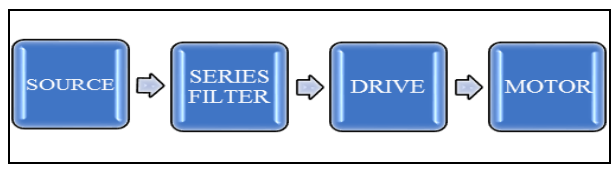

Fig. 1. Block diagram of Passive Series Filter 
Comparative Analysis of Series \& Parallel Passive... R. Jayswal, M. Shastri, S. Marathe, K. Panchal

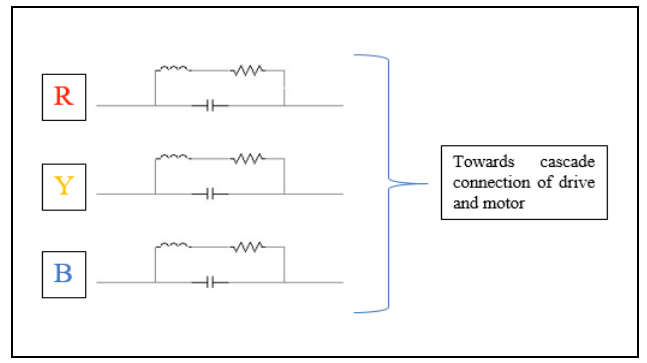

Fig. 2. Block diagram representing PSCAD replica for Passive Series Filter

\subsection{Passive Shunt Filter}

The passive shunt filter incorporates the application of either parallel resonance or series resonance mechanism. The RLC combination, acting as a series or parallel resonance for the passive harmonic filter is connected at the parallel point called the point of common coupling (PCC), which is somewhere between the input power supply and the load (Variable Frequency Drive cascaded induction motor) [2].

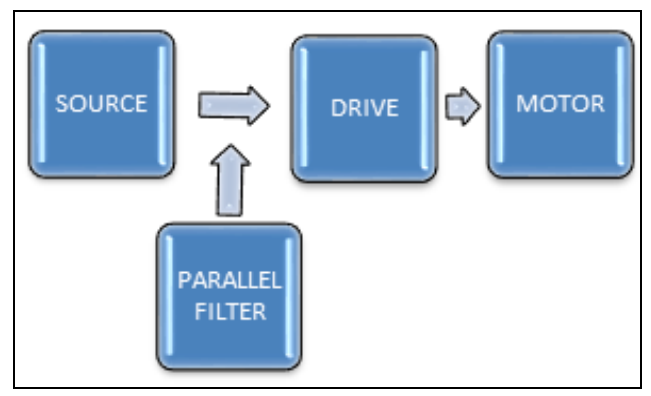

Fig. 3. Block diagram of Passive Shunt Filter

Parallel filter acts as an acceptor circuit, hence it will accept the current waveforms of tuned frequency because of the low impedance path and will ground it. That is, if the filter is designed to mitigate $5^{\text {th }}$ and $7^{\text {th }}$ order harmonic, the filter will allow all the corresponding order current waveforms to pass through it and ground it, because of the low impedance offered by the filter. 

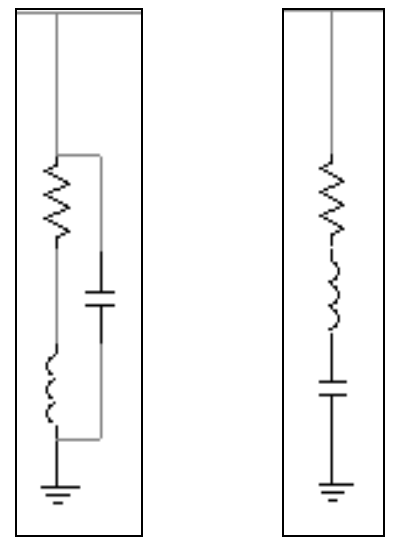

Fig. 3(a). Passive Shunt Filter (R and L $\| \mathrm{C}$ ) and Passive Shunt Filter (RLC Series)

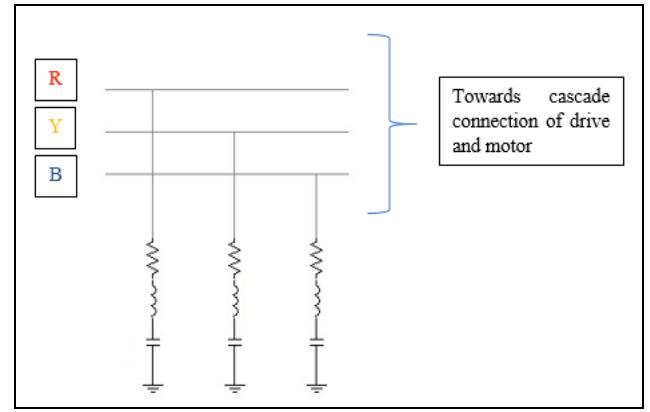

Fig. 4. Block diagram representing PSCAD replica for Passive Shunt Filter (RLC Series)

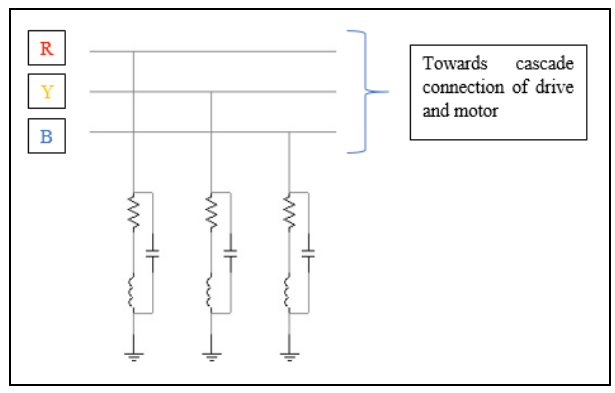

Fig. 5. Block diagram representing PSCAD replica for Passive Shunt Filter ( $\mathrm{R}$ and $\mathrm{L} \| \mathrm{C}$ )

\section{Analysis}

The analysis of the various topologies is made and various supporting simulation results were obtained from the PSCAD simulated model for the filter. For all the three topologies, 1 combination in series and 2 combinations in parallel, the results show first, the common source current, drawn by the load, the total harmonic distortion in the source current, and the individual harmonic distortion of the source current [4]. 
The supply to the PCC is from a $11 \mathrm{kV} / 440 \mathrm{~V}$ star-star connected transformer, whereas the load fed and controlled from the drive is a 5 HP 3 phase induction motor.

\subsection{For Source Current}

For non-linear load, an induction motor controlled by a variable frequency drive, in this case, the source current drawn by the load will be non-sinusoidal and will not follow the voltage waveform. The waveform of the distorted source current is as shown in fig. 6. As can be seen, the current waveform is of pulsating nature and has two pulses or spikes per half cycle. The discontinuity of the source current increase when the induction motor is operated below fundamental frequency provided by the drive, whereas if it is operated at the frequency higher than the fundamental frequency, the discontinuity of the waveform reduces and thus the waveform becomes fine and close to a sinusoidal one. Hence the waveform is discontinuous. Due to this addition of the distorted current waveform in the power system, the harmonics are introduced which results in heating of transformer, motor and other electrical equipment, vibrations of the inter-connected machines, which results in the various losses and thereby reducing the overall efficiency of the system.

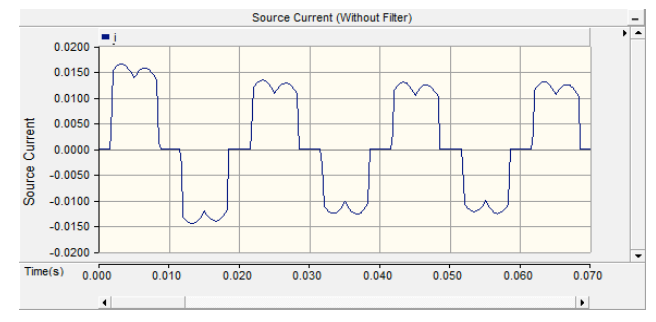

Fig. 6. Source current vs. time for the model not involving filter

After comparing the source currents drawn by various topologies (passive series filter) with the model without the filter it can be deduced that even after the application of the series topology filter, the distortion in the source current is finely reduced, but not fully diminished. Also, the magnitude of the current is seen to be fluctuating by $44.44 \%$ approximately, which can be seen in the fig. 7 .

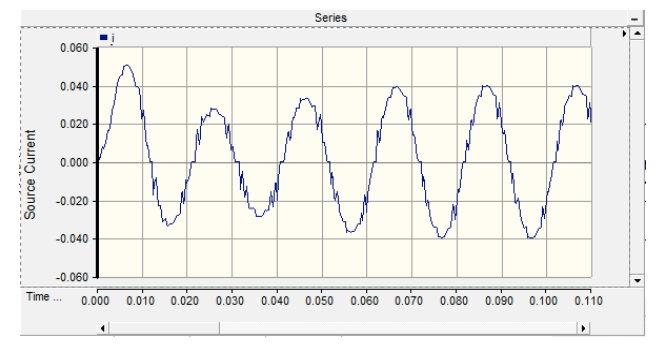

Fig. 7. Source current vs. time for the passive series filter

After the use of parallel topology including the series combination of the R, L and C, it can be noted that the distortion is almost removed and is nil, which can be seen in the fig. 8. Also, the magnitude of the drawn source current is uniform and not fluctuating as obtained in the case of passive shunt filter. 
Comparative Analysis of Series \& Parallel Passive... R. Jayswal, M. Shastri, S. Marathe, K. Panchal

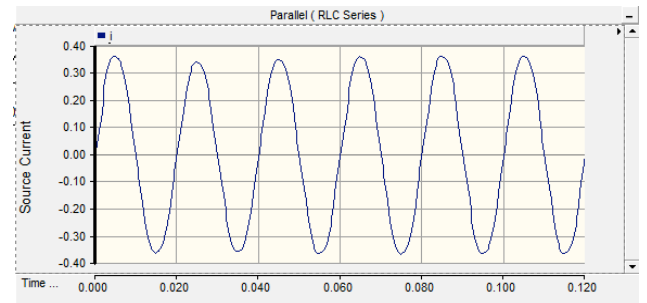

Fig. 8. Source current vs. time for the passive shunt filter having RLC series tuning

With the use of passive shunt filter including the series combination of $\mathrm{R}$ and $\mathrm{L}$ and then both in parallel with the $\mathrm{C}$, from fig. 9, it can be further deduced that, although the harmonics content is almost nil, the fluctuation in the source current magnitude is the maximum, with the percentage variation reaching $83 \%$.

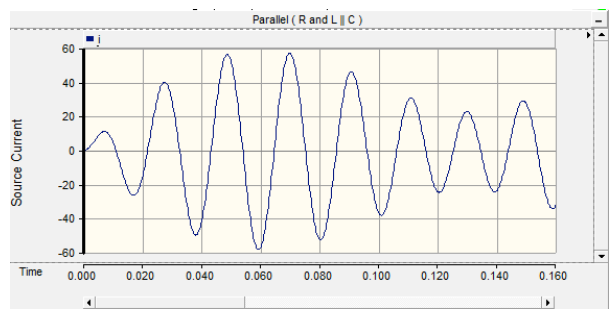

Fig. 9. Source current vs. time for the passive shunt filter having $\mathrm{R}$ and $\mathrm{L}$ in series with $\mathrm{C}$ connected in parallel with the $\mathrm{R}$ and $\mathrm{L}$ combination

Talking about the best topologies and keeping in mind the source current drawn by the nonlinear load, it can be finally concluded that the passive shunt filter with $\mathrm{R}, \mathrm{L}$ and $\mathrm{C}$ series combination gives the best output, with almost nil current distortion with uniform magnitude, and almost sinusoidal waveform current.

Furthermore, from fig. 6,7,8 and 9, it can be deduced that the magnitude of source current without filter and with filter is seen varying due to the fact that the line voltage applied to the motor is maintained constant in the same cases. If the line voltage is not maintained constant, then the desired comparable values can be obtained.

\subsection{For Total Harmonic Distortion}

Total harmonic distortion shown in fig. 10 to 13 is about the source current that is drawn and described about in the previous section detailing the analysis for source current. Fig. 10 shows the THD of the source current of the model without the use of filter, whereas fig. 11-13 shows the THD of the source current of the model when various topology filters are used in the system. 


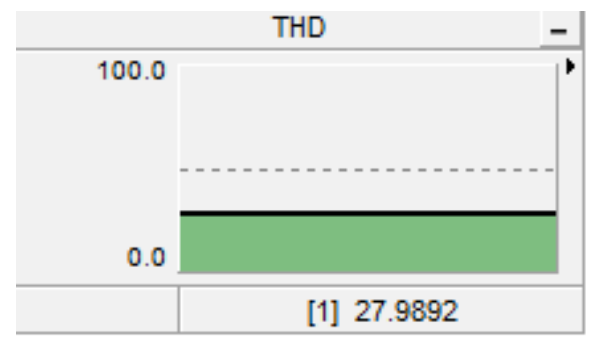

Fig. 10. Total Harmonic Distortion for the model not involving filter

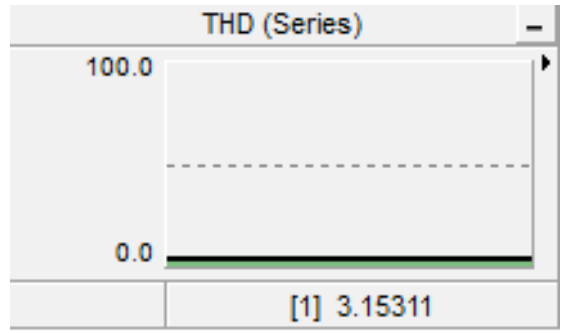

Fig. 11. Total Harmonic Distortion for source current of the passive series filter

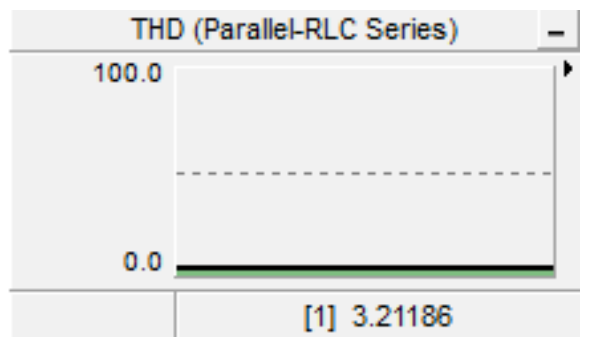

Fig. 12. Total Harmonic Distortion for source current the passive shunt filter having RLC series tuning

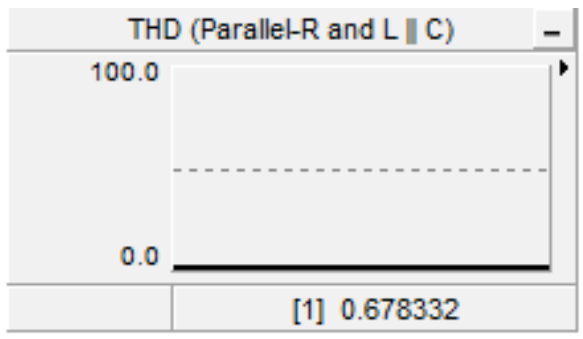

Fig. 13. Total Harmonic Distortion for source current of the passive shun filter having $R$ and $L$ in series with $C$ connected in parallel with the $\mathrm{R}$ and $\mathrm{L}$ combination

It can be concluded from above simulated observations, that the THD is the lowest in the passive shunt filter topology involving $\mathrm{R}$ and $\mathrm{L}$ in series combination, which is in parallel with the $\mathrm{C}$; followed by the passive shunt filter with $\mathrm{R}, \mathrm{L}$ and $\mathrm{C}$ in series and then the passive series filter, having 
the THD of $0.678 \%, 3.212 \%$ and $3.153 \%$ respectively. The THD obtained are worked out to be in the limits of the current distortion set by IEEE 519 (2014), as shown in table 2.

\subsection{For Individual Harmonic Distortion}

The simulations made here are done for the mitigation of $5^{\text {th }}$ and $7^{\text {th }}$ order harmonics from the source current drawn by the non-linear load. It can be seen from the figure 11 that $5^{\text {th }}$ and $7^{\text {th }}$ order are the dominating harmonics in the source current. After the application of the filter, the individual harmonics distortion is made to reduce by a noticeable amount.

From the fig. 15-17, it can be seen that the individual harmonics distortion is made almost nil for $5^{\text {th }}$ and $7^{\text {th }}$ order harmonics, although some amount is still present in $11^{\text {th }}$ and $13^{\text {th }}$ order current harmonics. The distortion is almost zero for the passive shunt filter involving $\mathrm{R}$ and $\mathrm{L}$ in series combination, and then in parallel with $\mathrm{C}$, which is followed by the rest of the 2 topologies.

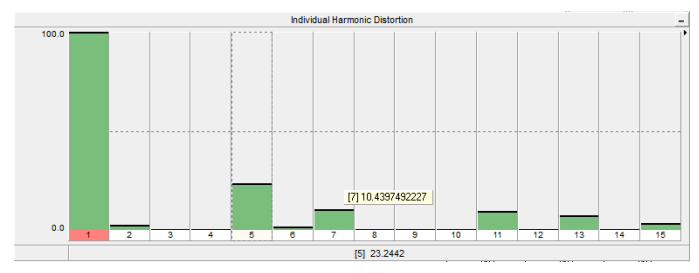

Fig. 14. Individual Harmonic Distortion for source current of the model not involving filter

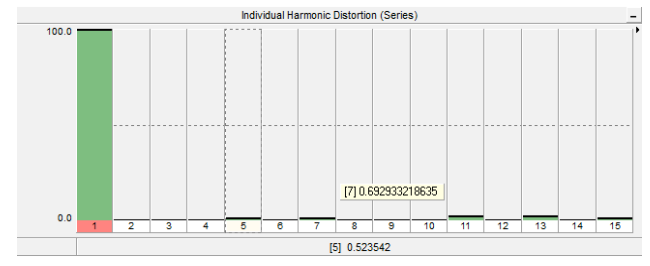

Fig. 15. Individual Harmonic Distortion for source current of the passive series filter

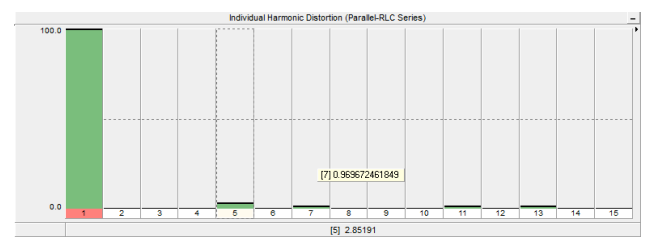

Fig. 16. Individual Harmonic Distortion for source current the passive shunt filter having RLC series tuning

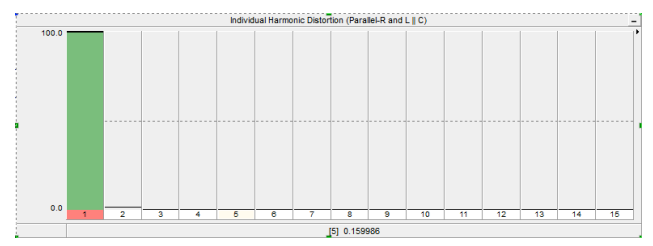

Fig. 17. Individual Harmonic Distortion for source current of the passive shunt filter having $R$ and $L$ in series with $\mathrm{C}$ connected in parallel with the $\mathrm{R}$ and $\mathrm{L}$ combination 


\section{Comparison, Verdict and Future Scopes}

Table 1 shows the comparison of the three topologies used herewith, based on various parameters, such as spikes, active power, reactive power, harmonics (total harmonics distortion) and finally the cost and size are compared. In the table 1, THD values are for the filter used for mitigating only $5^{\text {th }}$ order harmonics. In table 2 , Isc is the maximum short circuit current and IL is the maximum load current demand. [6]

\subsection{Future Scopes}

We can use active filter instead of passive filter because to eliminate particular harmonic, separate filter is required. Moreover, by improving the $\mathrm{Q}$ factor, cost of the passive filter can be reduced. This all configuration can be tested in hardware with different non-linear loads. For further more advancement, hybrid passive filters can also be taken into consideration.

\begin{tabular}{|c|l|c|c|c|}
\hline Sr. No. & \multicolumn{1}{|c|}{ Parameter } & Series & Parallel (RLC series) & Parallel (R and L $\| \mathbf{C})$ \\
\hline $\mathbf{1}$ & Spikes & Present & Negligible & Nil (uneven magnitude) \\
\hline $\mathbf{2}$ & Harmonics (THD) & 3.153 & 3.212 & 0.6783 \\
\hline $\mathbf{3}$ & Cost & Cheap & Expensive & Very Expensive \\
\hline $\mathbf{4}$ & Size & Small & Medium & Large \\
\hline
\end{tabular}

TABLE 1. Comparison of the three topologies used based on various parameters

\begin{tabular}{|c|c|c|c|c|c|c|}
\hline Isc/ IL & $\mathbf{H}<\mathbf{1 1}$ & $\mathbf{1 1}<\mathbf{h}<\mathbf{1 7}$ & $\mathbf{1 7}<\mathbf{h}<\mathbf{2 3}$ & $\mathbf{2 3}<\mathbf{h}<\mathbf{3 5}$ & $\mathbf{h}>\mathbf{3 5}$ & TDD \\
\hline$<20$ & 4.0 & 2.0 & 1.5 & 0.6 & 0.3 & 5.0 \\
\hline $20-50$ & 7.0 & 3.0 & 2.5 & 1.0 & 0.5 & 8.0 \\
\hline $50-100$ & 10.0 & 4.0 & 4.0 & 1.5 & 0.7 & 12.0 \\
\hline $100-1000$ & 12.0 & 5.0 & 5.0 & 2.0 & 1.0 & 15.0 \\
\hline$>1000$ & 15.0 & 7.0 & 6.0 & 2.5 & 1.4 & 20.0 \\
\hline
\end{tabular}

TABLE 2. Current distortion Limit by IEEE 519 (2014)

\section{Conclusion}

To conclude, it can be said that passive series filter provides high impedance to the source harmonic current, because it is highly inductive in nature and low capacitance. Series passive filter will block the source harmonic current, hence induce spikes in the source current. Whereas in case of passive shunt filter, low impedance path is offered to the source harmonic current due to which, the filter is highly capacitive in nature with lower inductance. Comparing both, passive series and passive 
Comparative Analysis of Series \& Parallel Passive... R. Jayswal, M. Shastri, S. Marathe, K. Panchal

shunt filter, it can be finally concluded that if economical barrier is considered, then passive series filter is beneficial, whereas if technical background is the criteria, then passive shunt filter with R, L and $\mathrm{C}$ in series combination is preferred.

\section{References}

[1] Pranjali Bafila, "Power Quality improvement using passive shunt filter", International Journal of Enhanced Research in Science Technology \& Engineering", Vol. 4 Issue 6, June-2015, pp: (371-378).

[2] Z. A. Memon, M. A. Uquaili, M. A. Unar, "Harmonics mitigation of industrial power system using passive filters ", Mehran University Research Journal of Engineering and Technology, vol. 31, no 2, p. 355-360, April 2012.

[3] Mojgan Hojabri and Mehrdad Hojabri, "Design, Application and Comparison of Passive Filters for ThreePhase Grid-Connected Renewable Energy Systems", ARPN Journal of Engineering and Applied Sciences, VOL. 10, NO. 22, DECEMBER, 2015, pp. 10691-10697

[4] Kumar Reddy Cheepati, Sardar Ali and Surya Kalavathi M., "Performance Analysis of Double Tuned Passive Filter for Power Quality", I J C T A, 9(7), 2016, pp. 3295-3305

[5] Srijan Saha, Suman Das, Champa Nandi, "Harmonics Analysis of Power Electronics Loads", International Journal of Computer Applications (0975-8887), Volume 92 - No. 10, April 14

[6] Mandeep Singh and Sheila Mahapatra, "Implementation of Passive Filters for Harmonics Reduction ", International Journal of Advanced Science and Technology Vol.78 (2015), pp.1-12

[7] S. K. Purushothaman, "A Quantitative Approach to Minimize Harmonics Elimination Using Filter Design", International Journal of Advanced Research in Computer Science and Software Engineering, Volume 3, Issue 12, December 2013, pp. 568-572

[8] M. Jayaraman, V.T. Sreedevi, R. Balakrishnan, "Analysis and design of passive filters for power quality improvement in standalone PV systems ", Engineering (NUiCONE), Nirma University International Conference, pp.1-6, 28-30 Nov. 2013. 